\title{
Synthesis of Hyaluronic Acid Oligomers using
}

\section{$\mathrm{Ph}_{2} \mathrm{SO} / \mathrm{Tf}_{2} \mathrm{O}$ Mediated Glycosylations}

Jasper Dinkelaar, Jeroen D. C. Codée, Herman S. Overkleeft, Gijsbert A. van der Marel*.

Leiden Institute of Chemistry, Leiden University, P.O. Box 9502,

2300 RA Leiden, The Netherlands,

marel_g@chem.leidenuniv.nl

Index

General methodes

S-2

NMR spectra of compound 1

S-3/4

NMR spectra of compound 2

S-5/6

NMR spectra of compound 3

S-7/8

NMR spectra of compound 4

NMR spectra of compound 5

S-11/12

NMR spectra of compound 6

S-13/14

NMR spectra of compound 7

S-15/16

NMR spectra of compound 8

S-16/18

NMR spectra of compound 9

S-19/20

NMR spectra of compound 10

S-21/22

NMR spectra of compound 11

$\mathrm{S}-23 / 24$

NMR spectra of compound 12

$\mathrm{S}-25 / 26$

NMR spectra of compound 13

S-27/28

NMR spectra of compound 14

S-29/30 
General methods: Dichloromethane was refluxed with $\mathrm{P}_{2} \mathrm{O}_{5}$ and distilled before use. Trifluoromethanesulfonic anhydride was distilled from $\mathrm{P}_{2} \mathrm{O}_{5}$. Traces of water in the donor and acceptor glycosides, diphenylsulfoxide and TTBP were removed by co-evaporation with toluene. TTBP was synthesized as described by Crich et al. ${ }^{1}$ All other chemicals were used as received. Column chromatography was performed on Merck silica gel $60(0.040-0.063 \mathrm{~mm})$. TLC analysis was conducted on HPTLC aluminum sheets (Merck, silica gel 60, F245). Compounds were visualized by UV absorption $(245 \mathrm{~nm})$, by spraying with $20 \% \mathrm{H}_{2} \mathrm{SO}_{4}$ in ethanol or with a solution of $\left(\mathrm{NH}_{4}\right)_{6} \mathrm{Mo}_{7} \mathrm{O}_{24} \cdot 4 \mathrm{H}_{2} \mathrm{O} 25 \mathrm{~g} / \mathrm{L},\left(\mathrm{NH}_{4}\right)_{4} \mathrm{Ce}\left(\mathrm{SO}_{4}\right)_{4} \cdot 2 \mathrm{H}_{2} \mathrm{O} 10 \mathrm{~g} / \mathrm{L}, 10 \% \mathrm{H}_{2} \mathrm{SO}_{4}$ in $\mathrm{H}_{2} \mathrm{O}$ followed by charring at $+/-140{ }^{\circ} \mathrm{C}$. NMR spectra were recorded in $\mathrm{CDCl}_{3}$ with chemical shift $(\delta)$ relative to tetramethylsilane unless stated otherwise. NMR peak assignments were based on ${ }^{1} \mathrm{H}$ COSY and HSQC experiments. IR spectra are reported in $\mathrm{cm}^{-1}$.

\footnotetext{
${ }^{1}$ Crich, D.; Smith, M.; Yao, Q.; Picione, J. Synthesis, 2001, 323-326.
} 

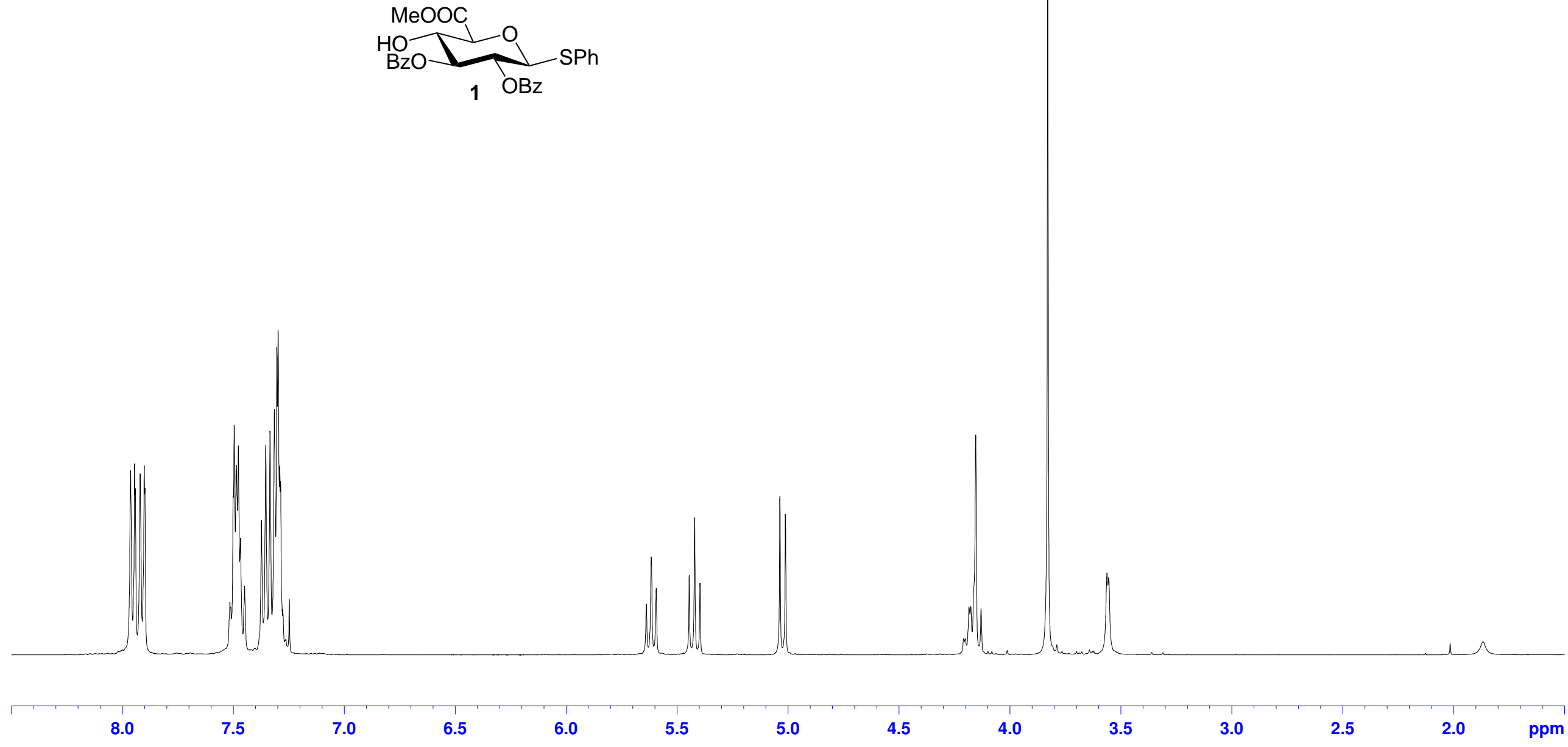


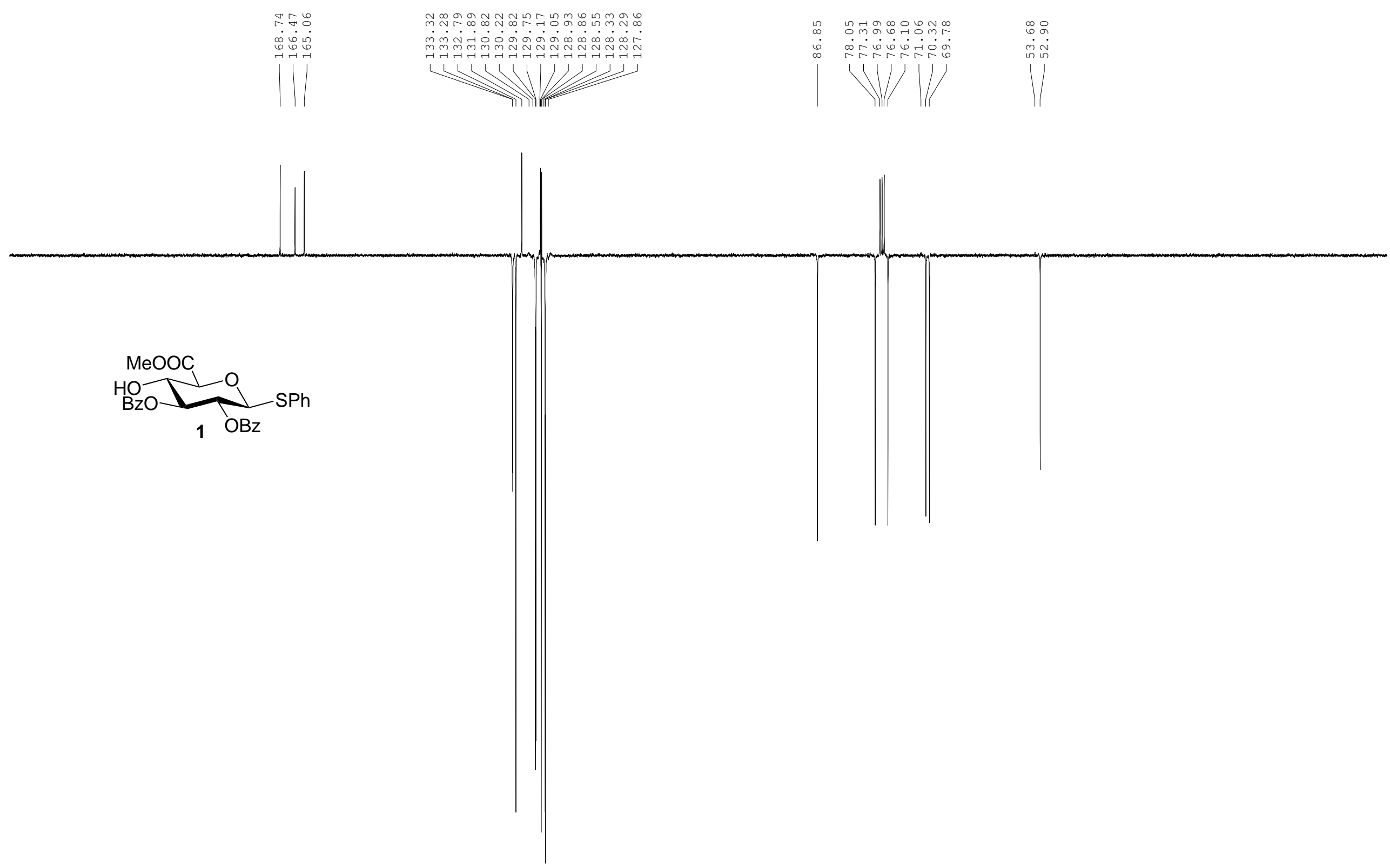




\section{$\mathrm{MeOOC}$}
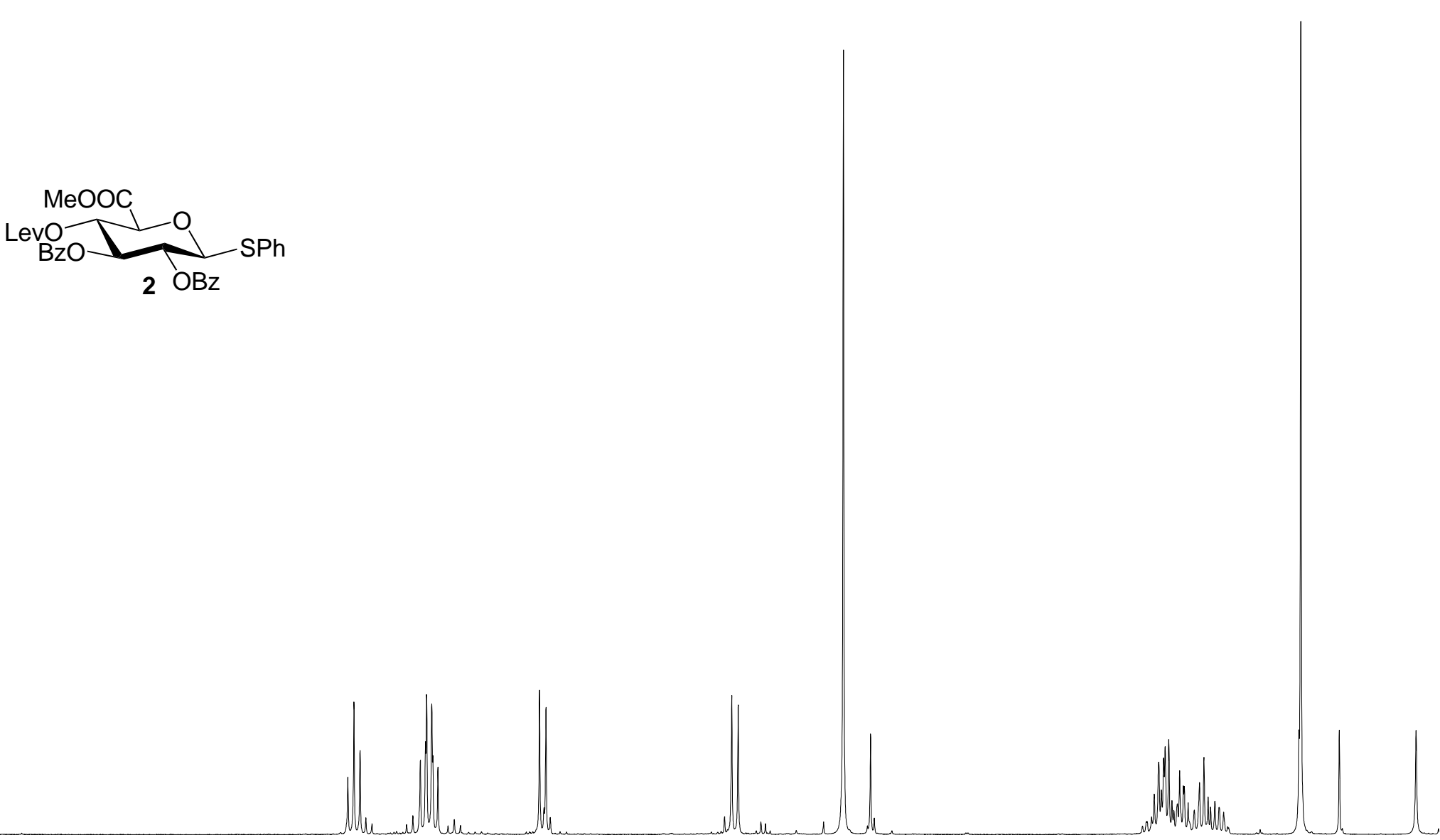


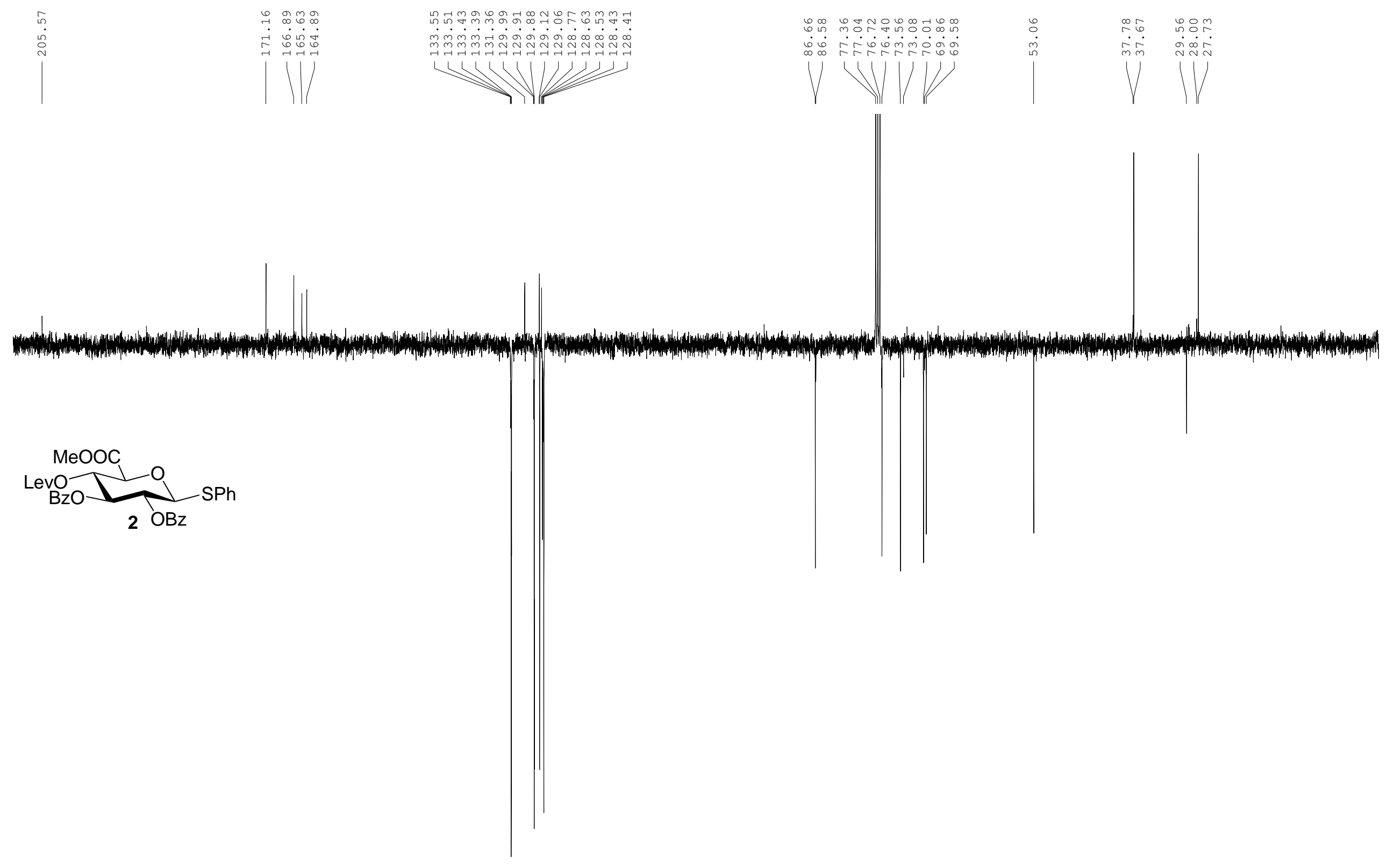




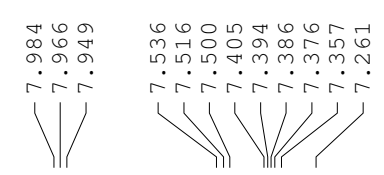

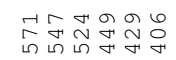

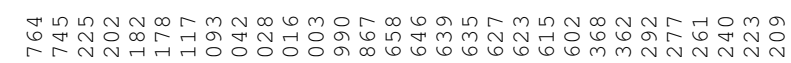

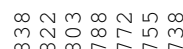

1

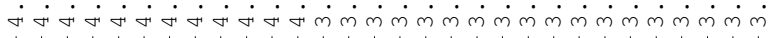

$\mathrm{MeOOC}$

$\mathrm{N}_{3}$

$\mathrm{HO}$

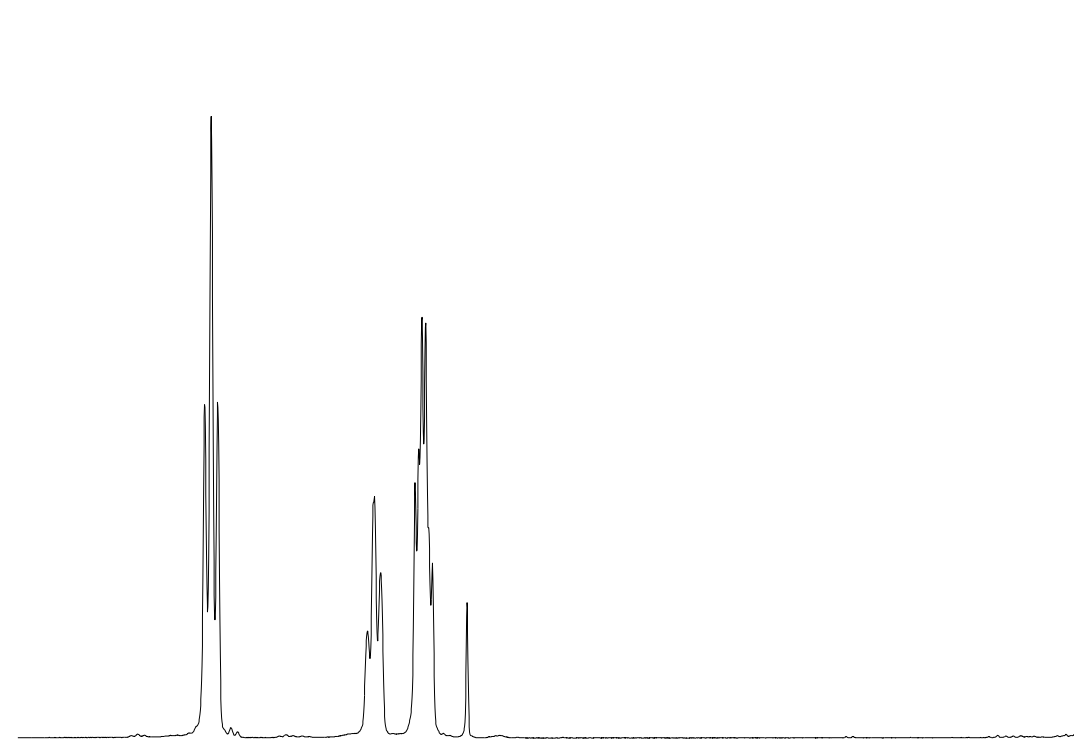




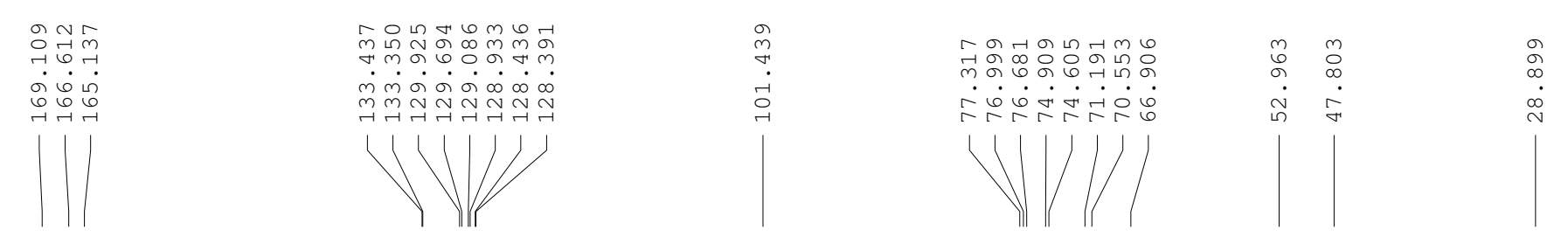

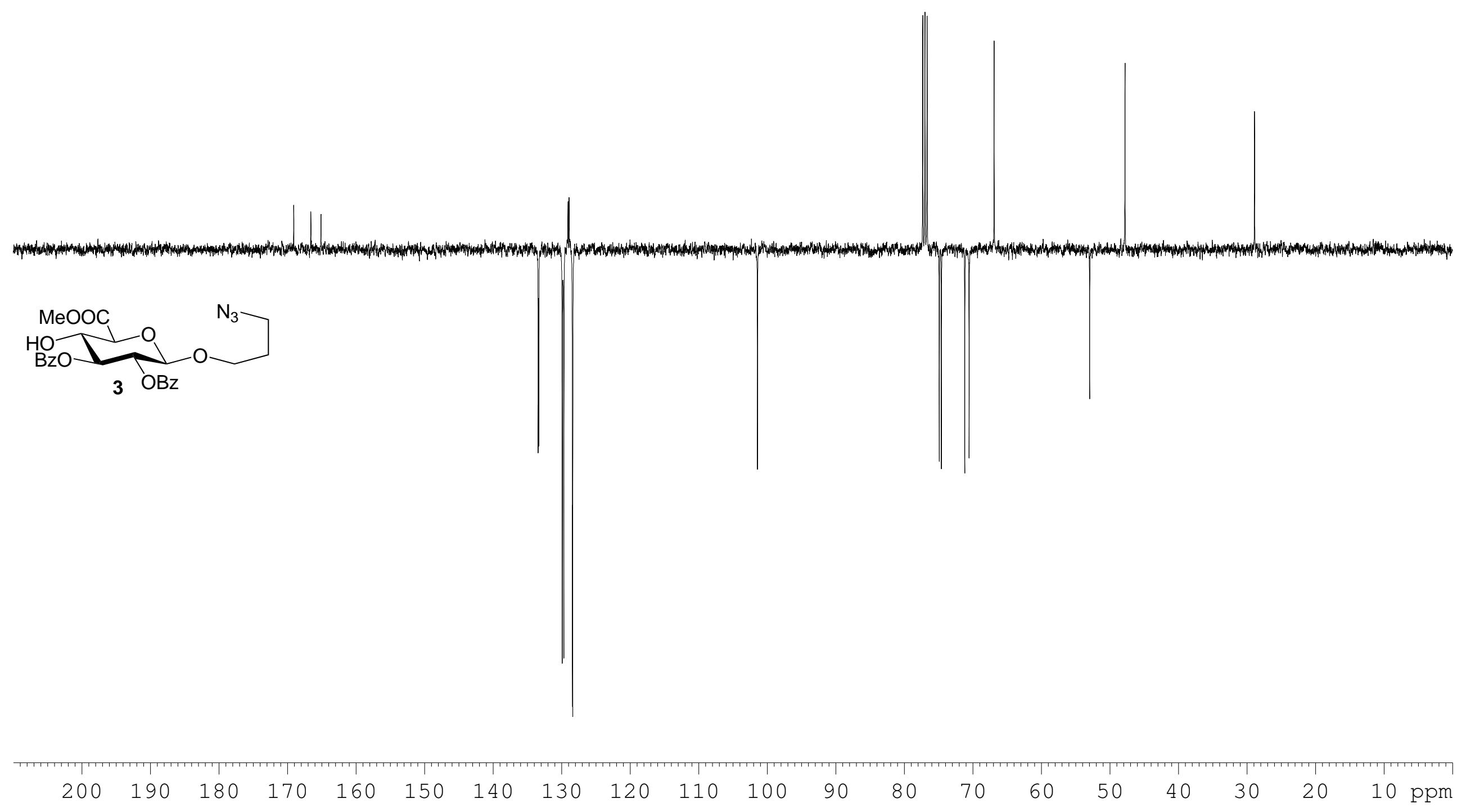




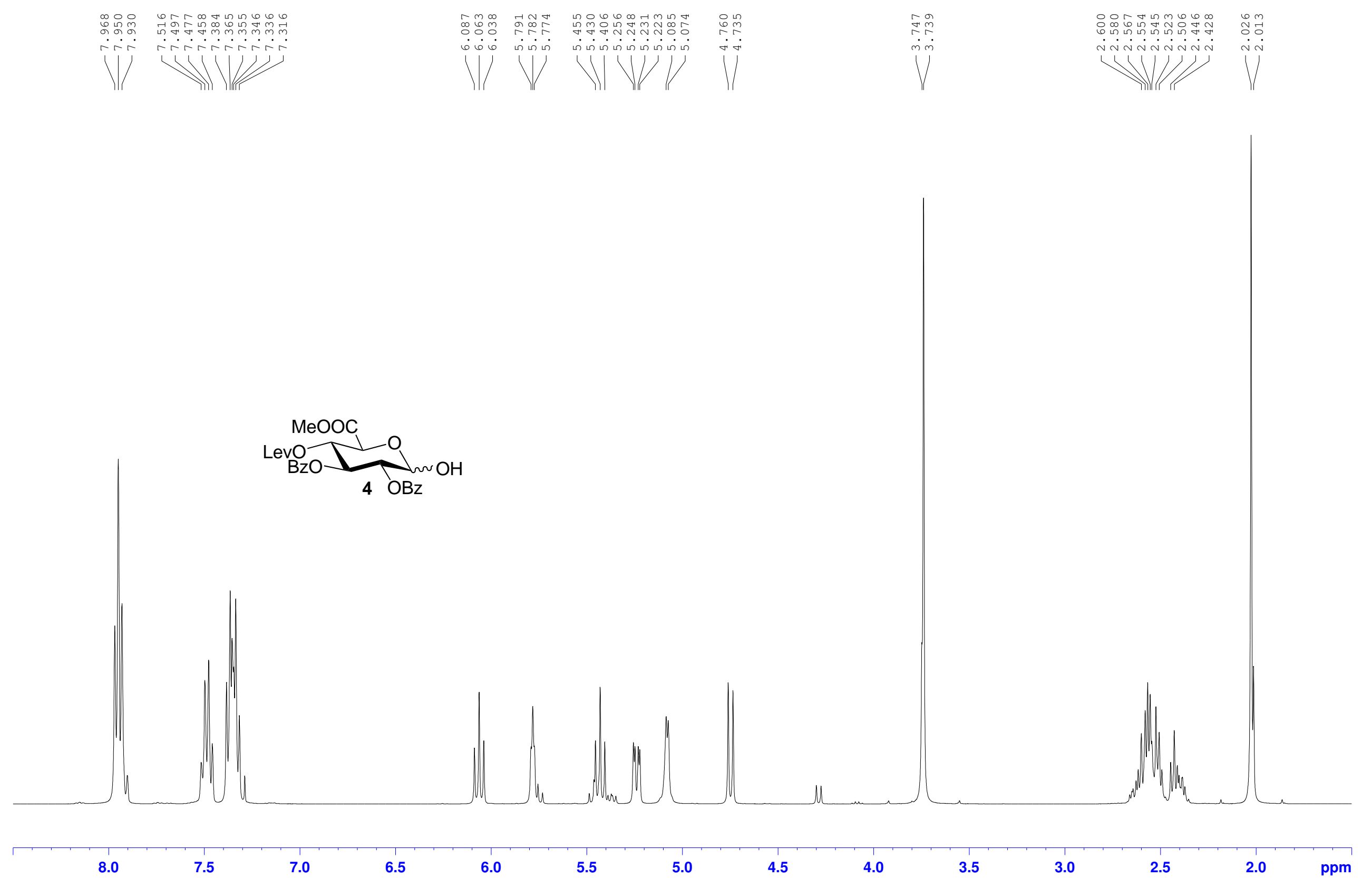




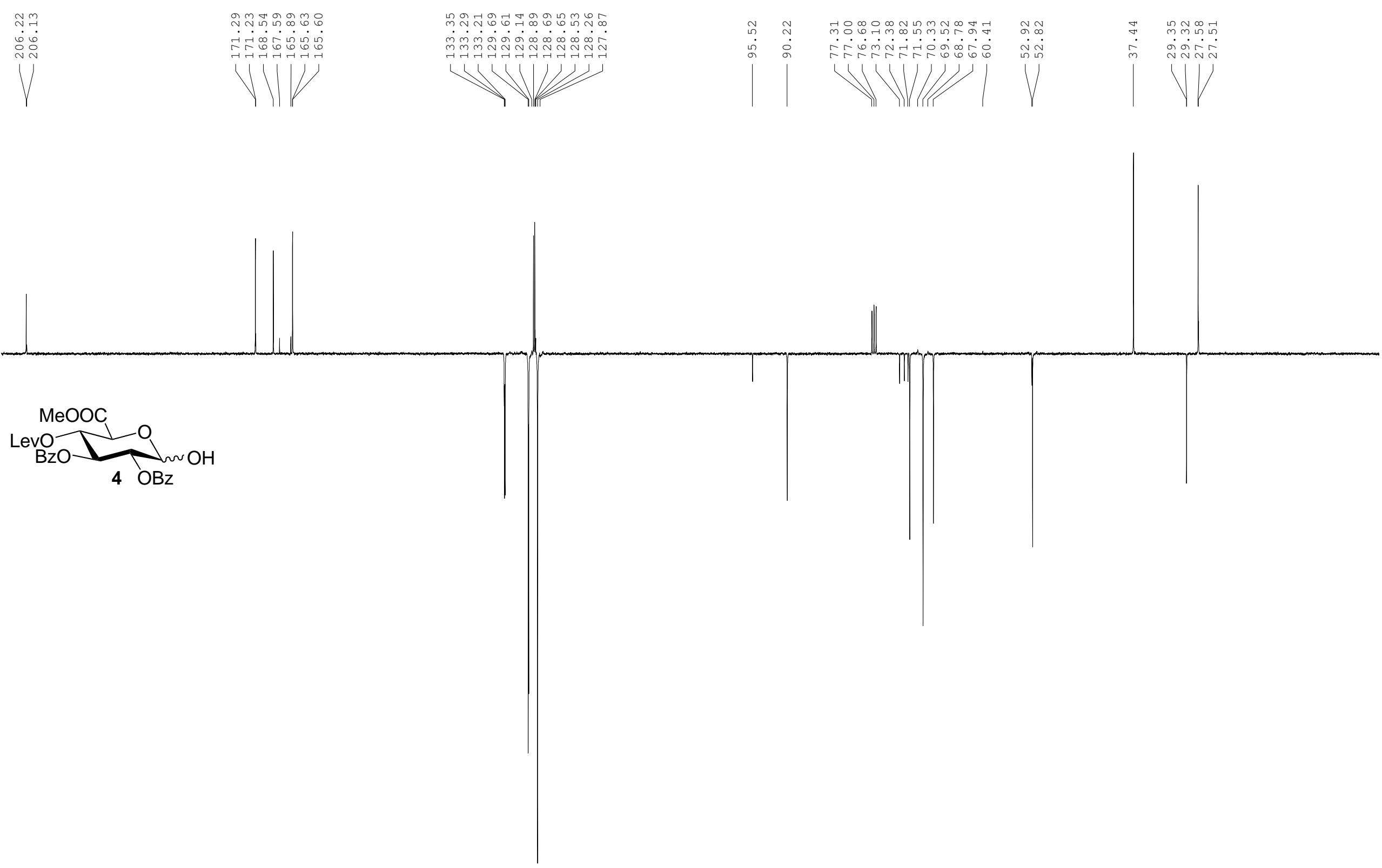




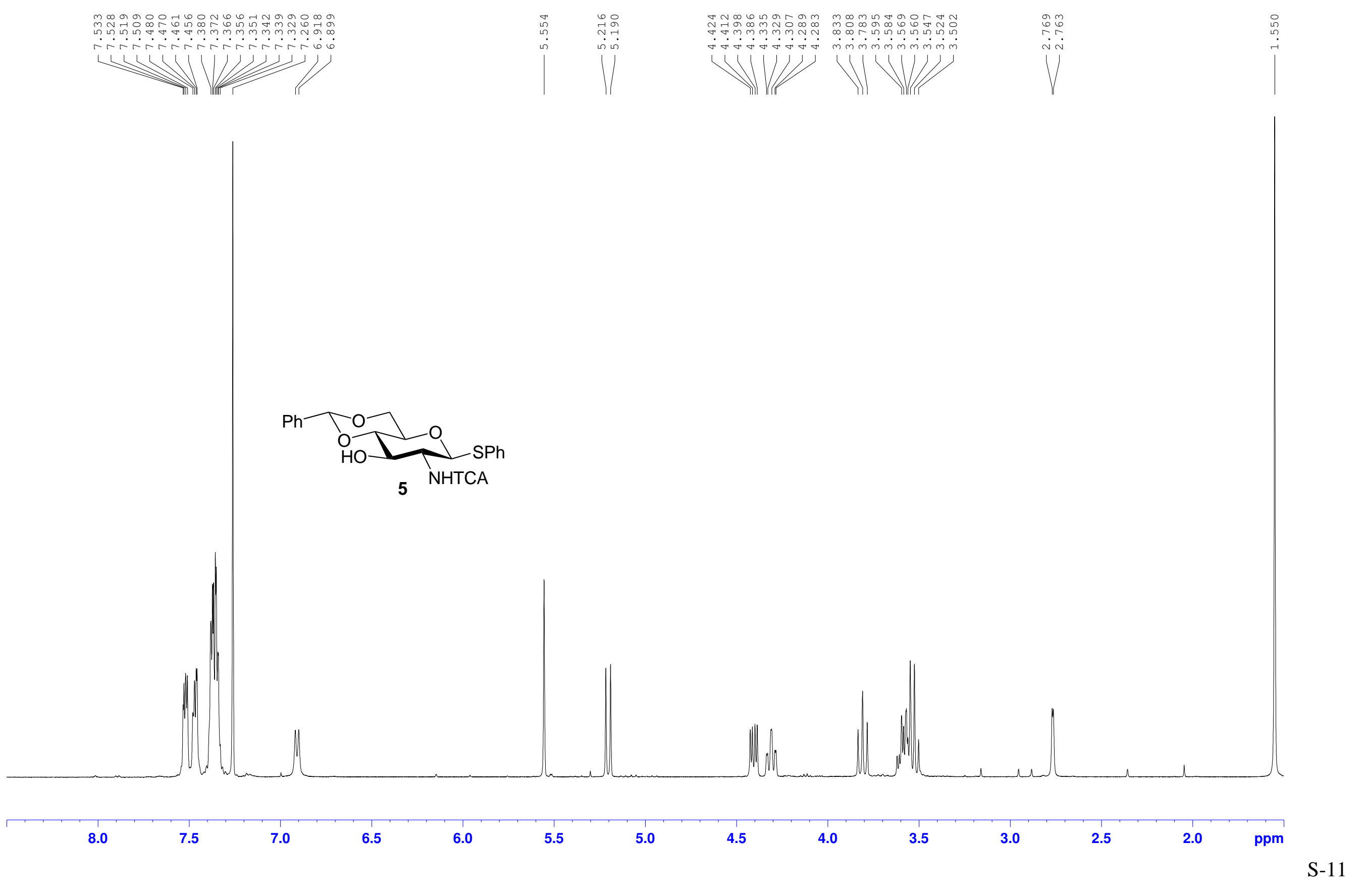




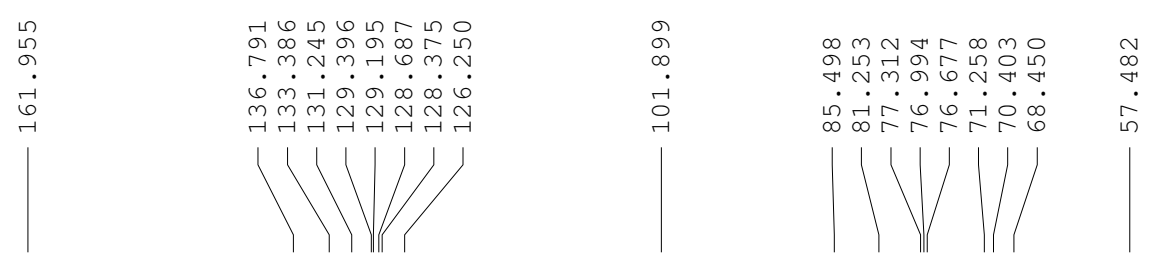

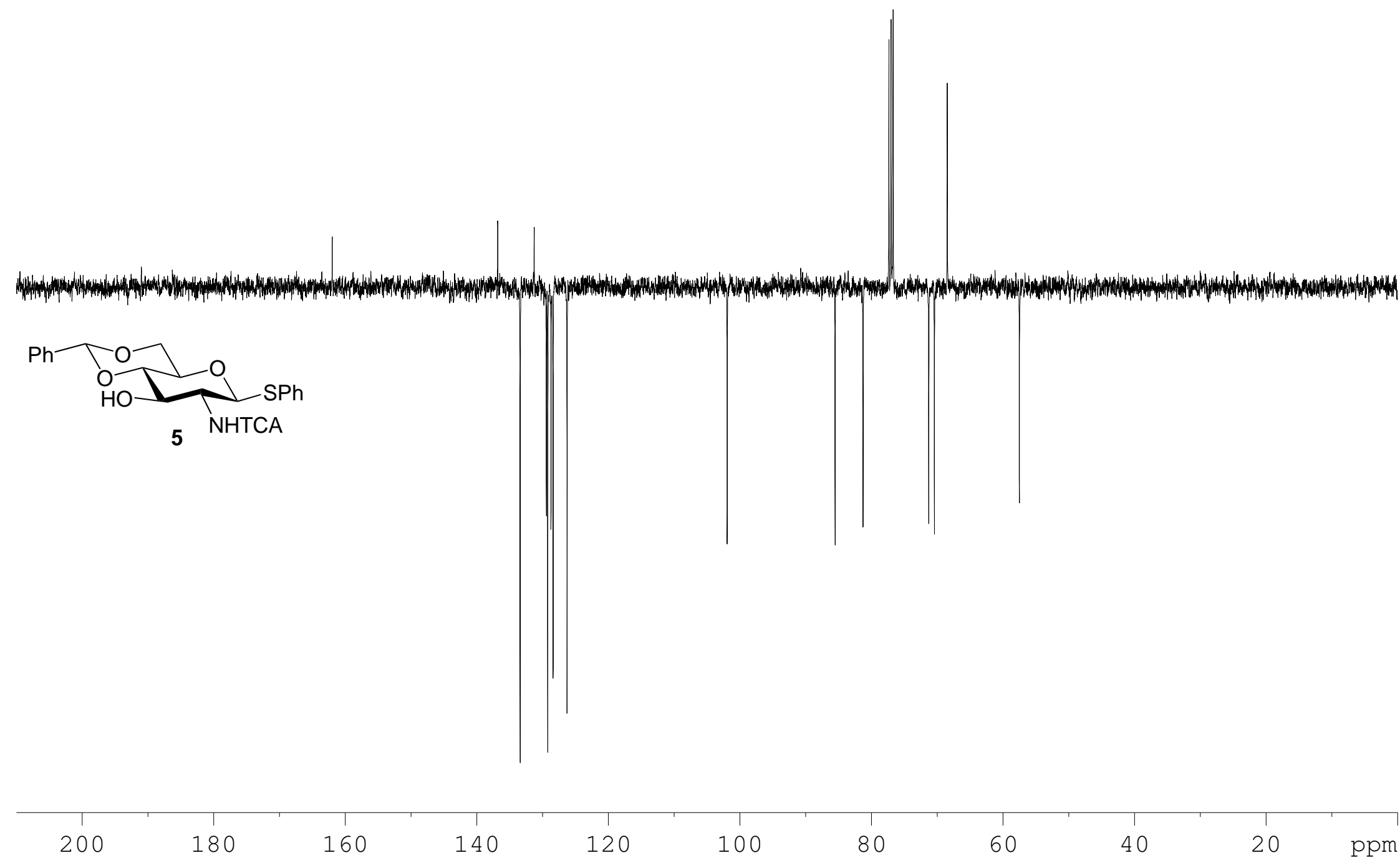




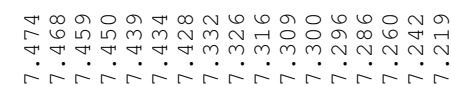

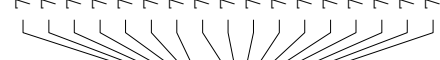

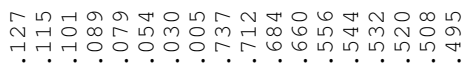

WUHU UHHUH

年

UV
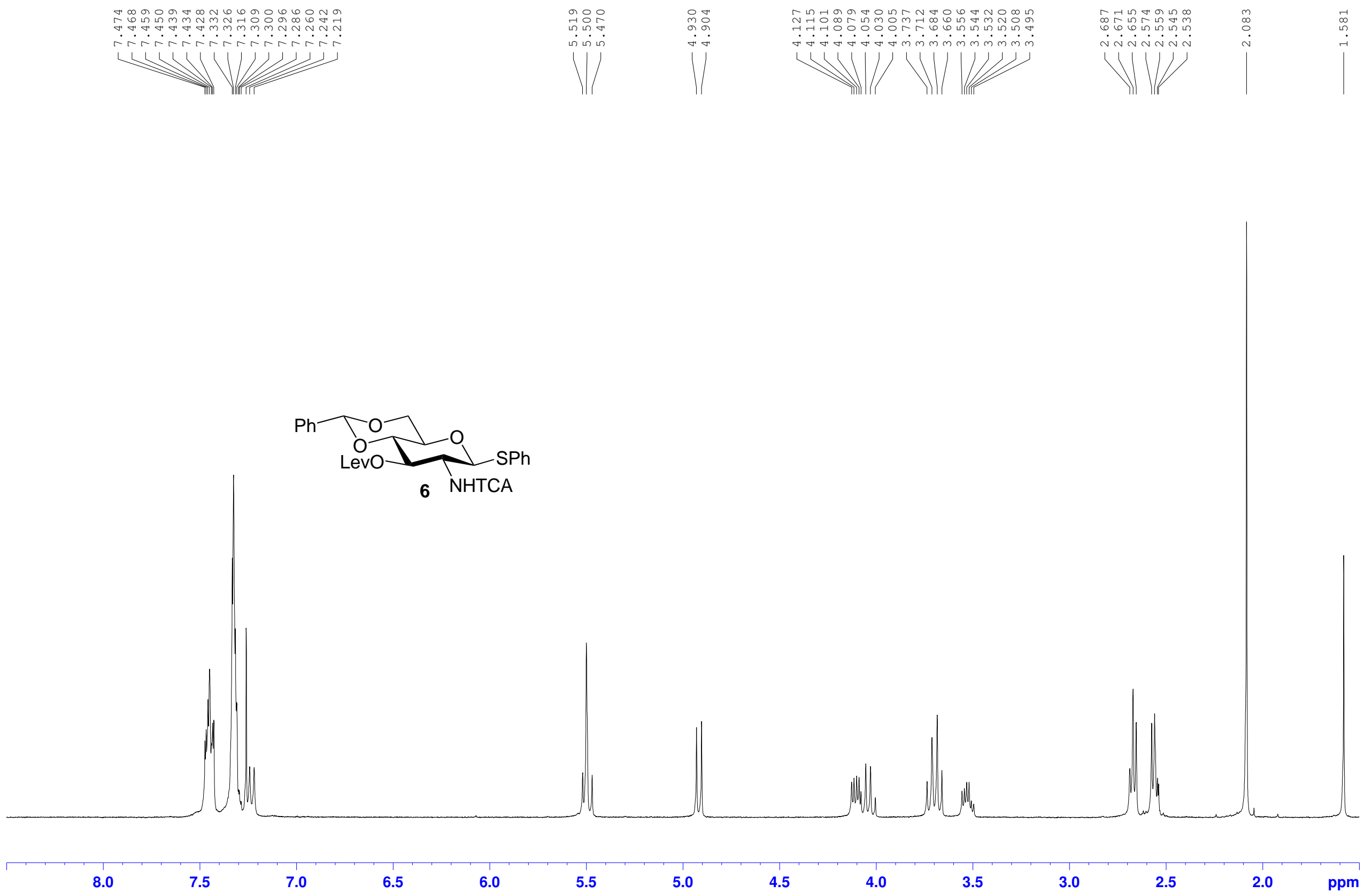


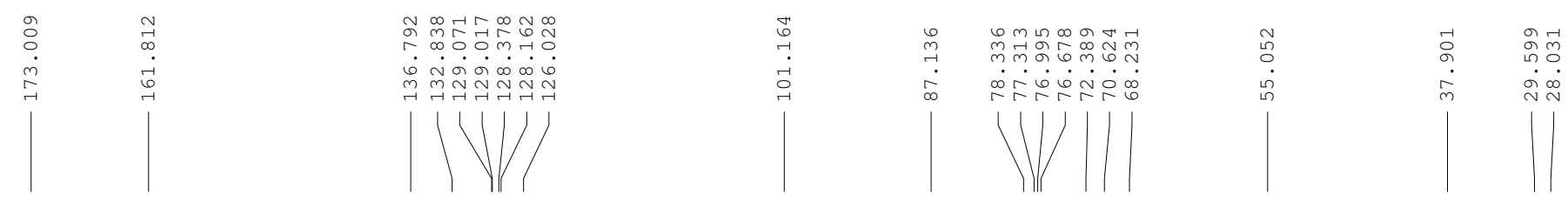

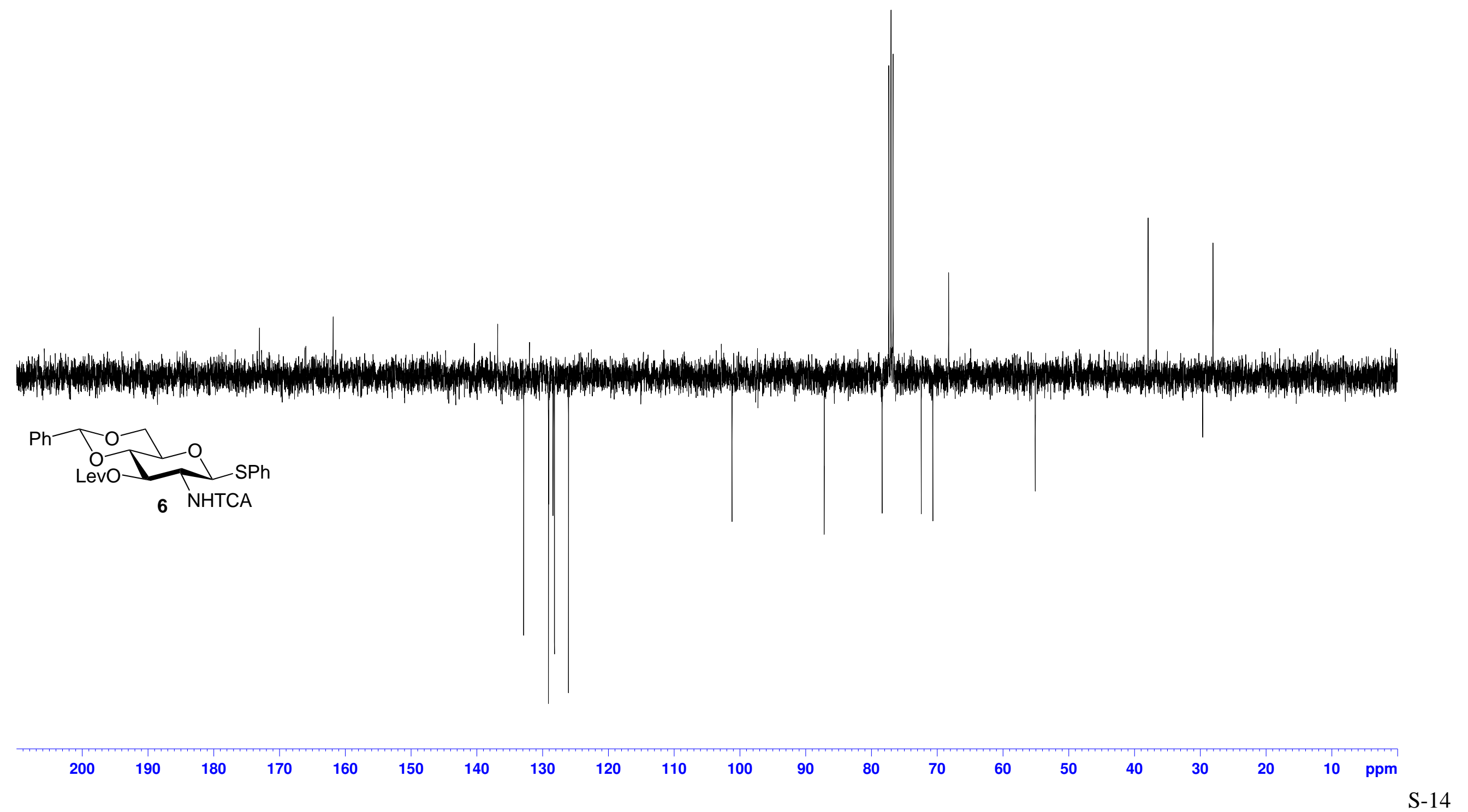




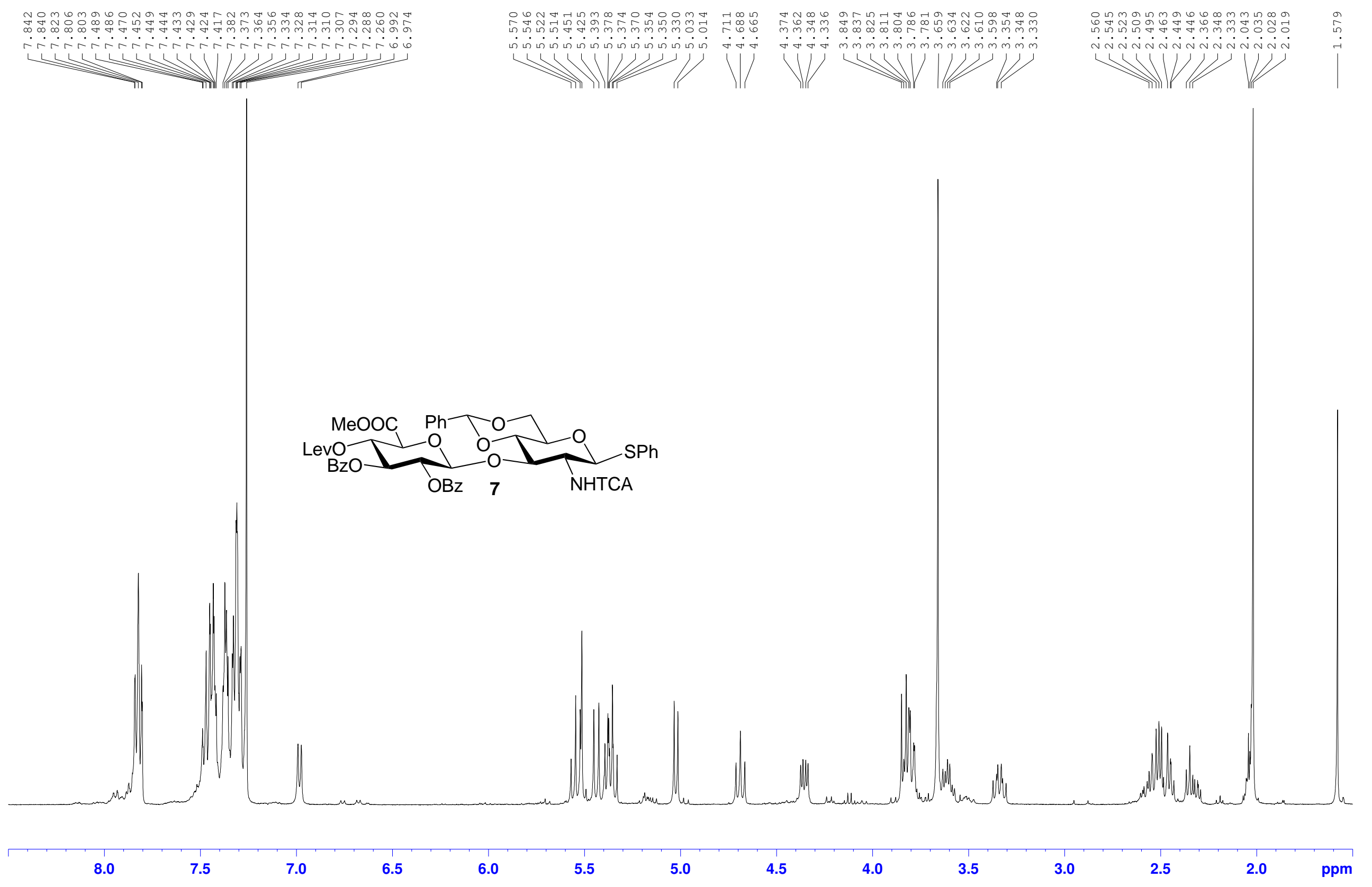









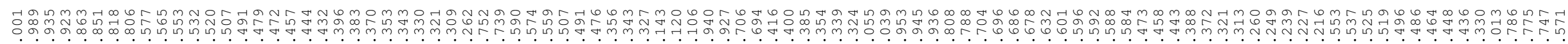

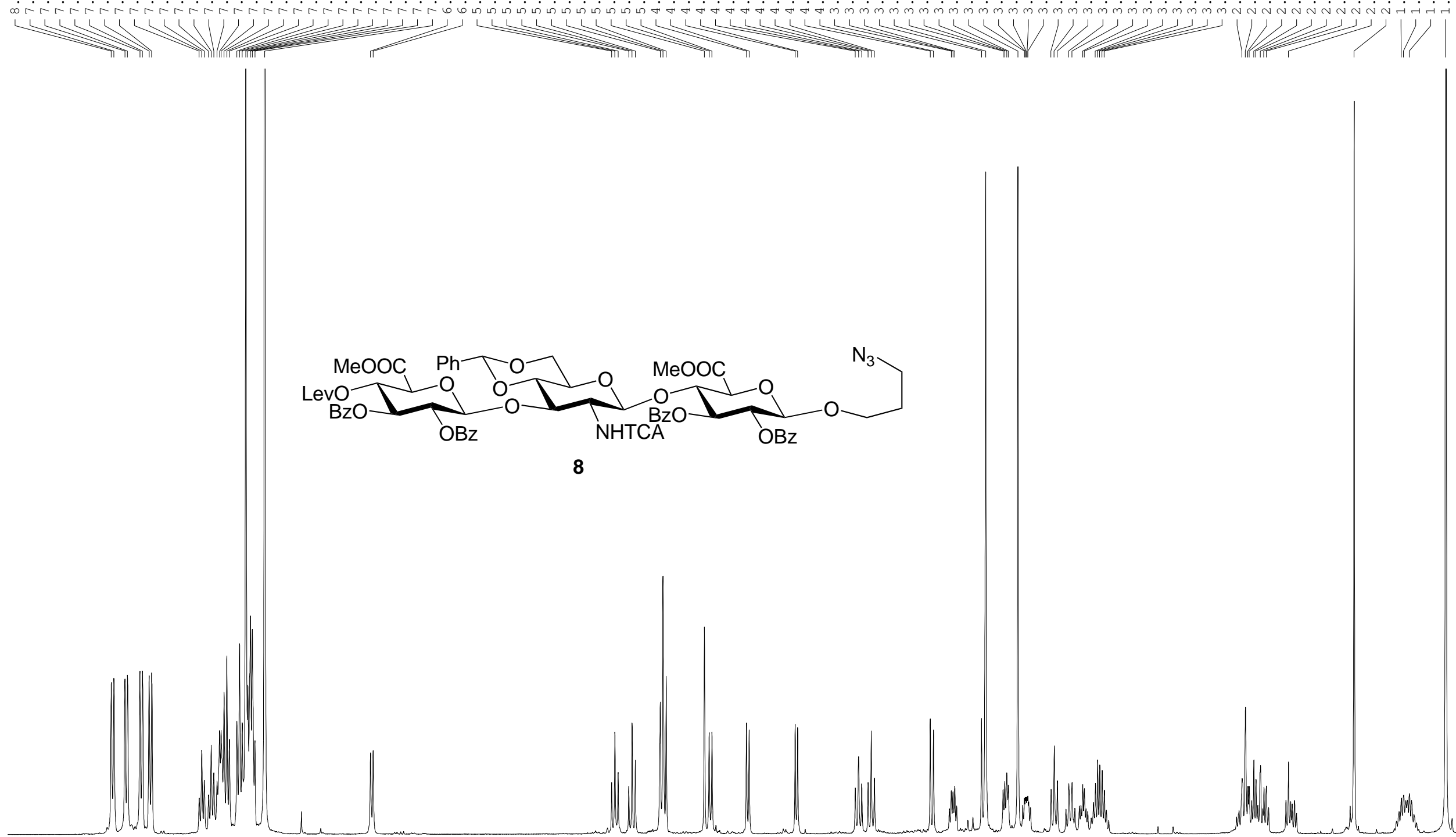




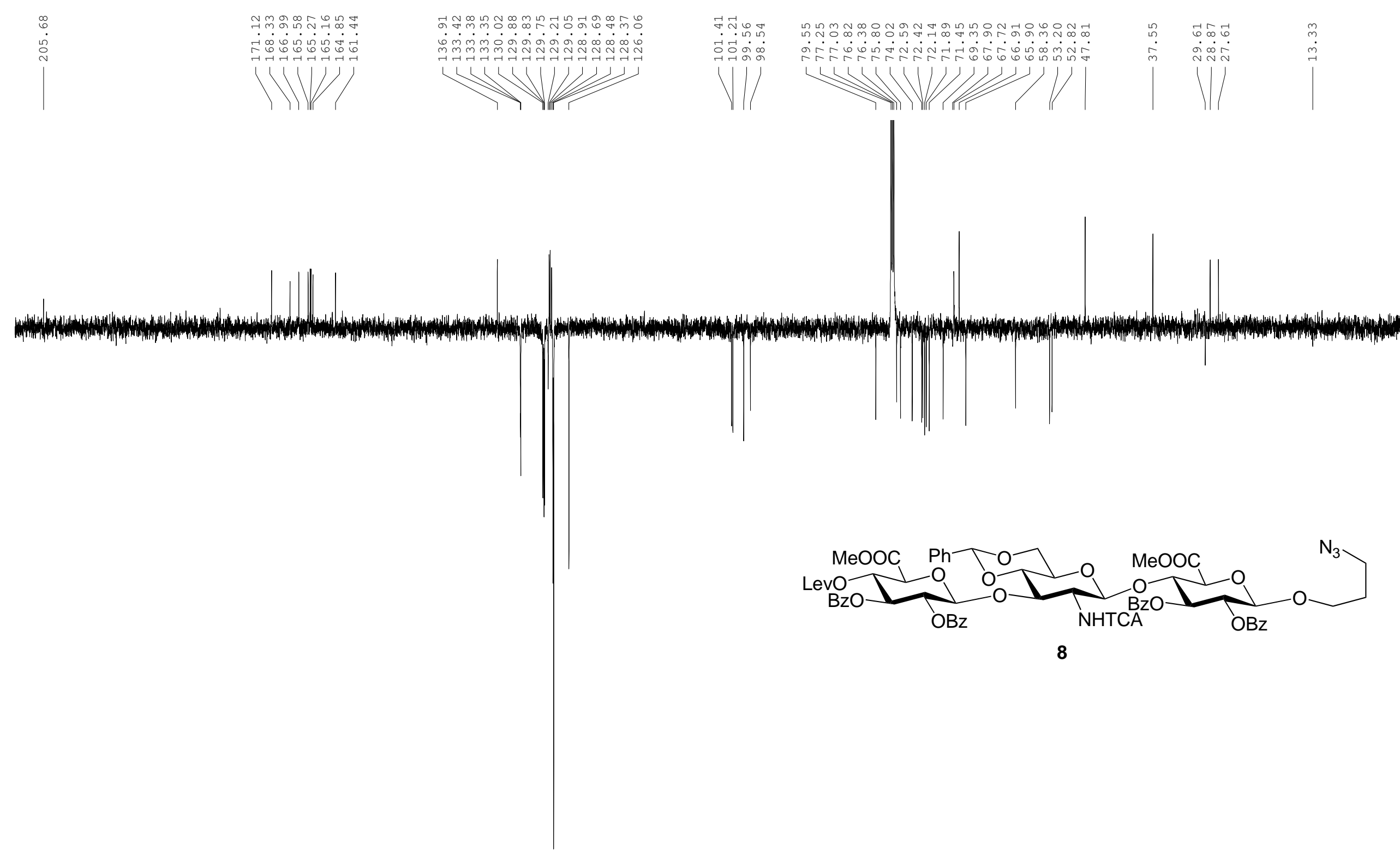




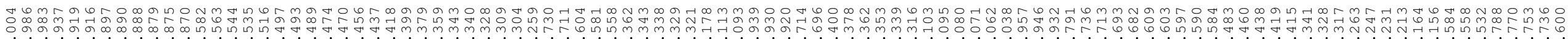

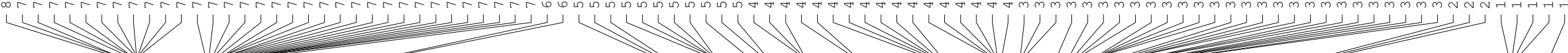

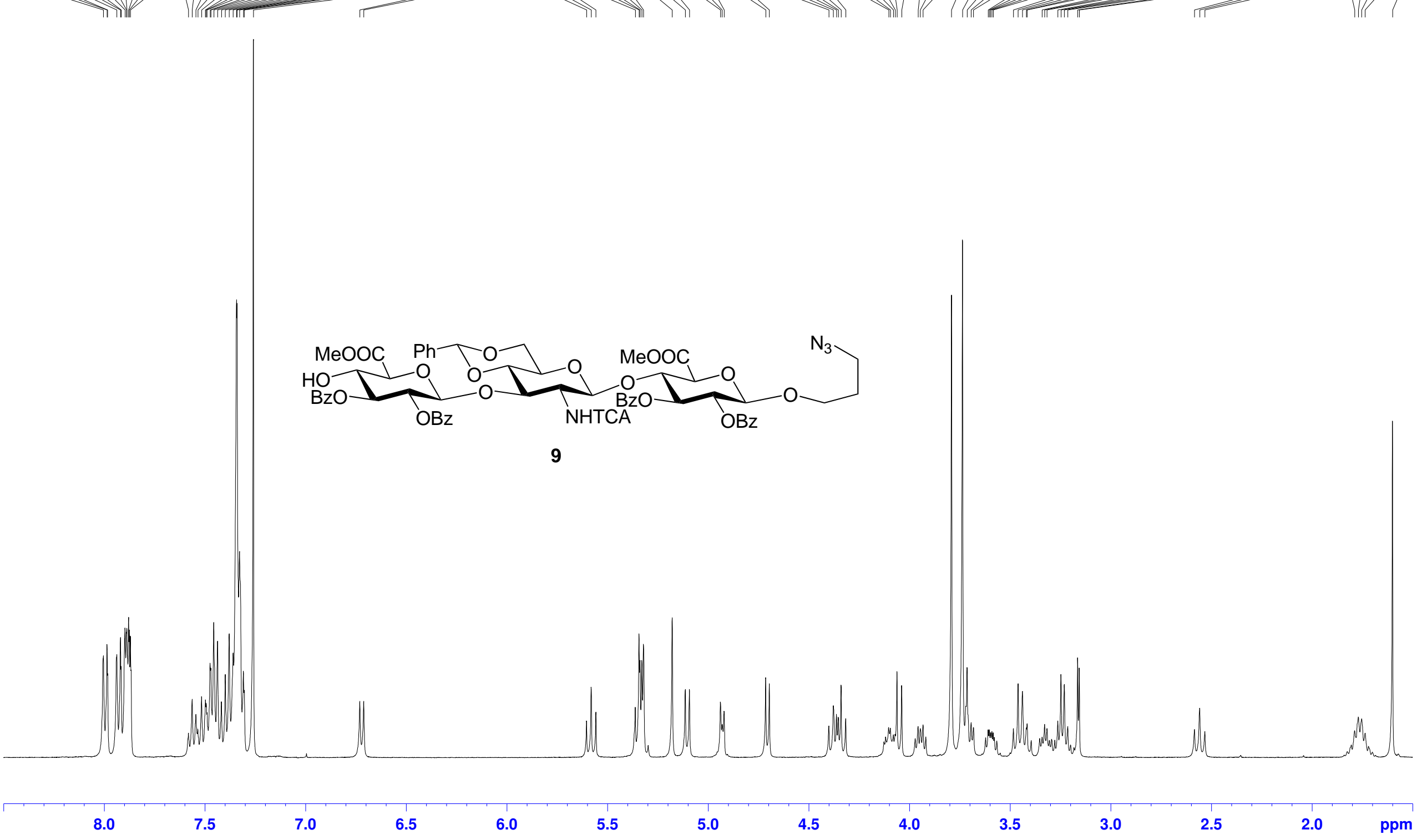




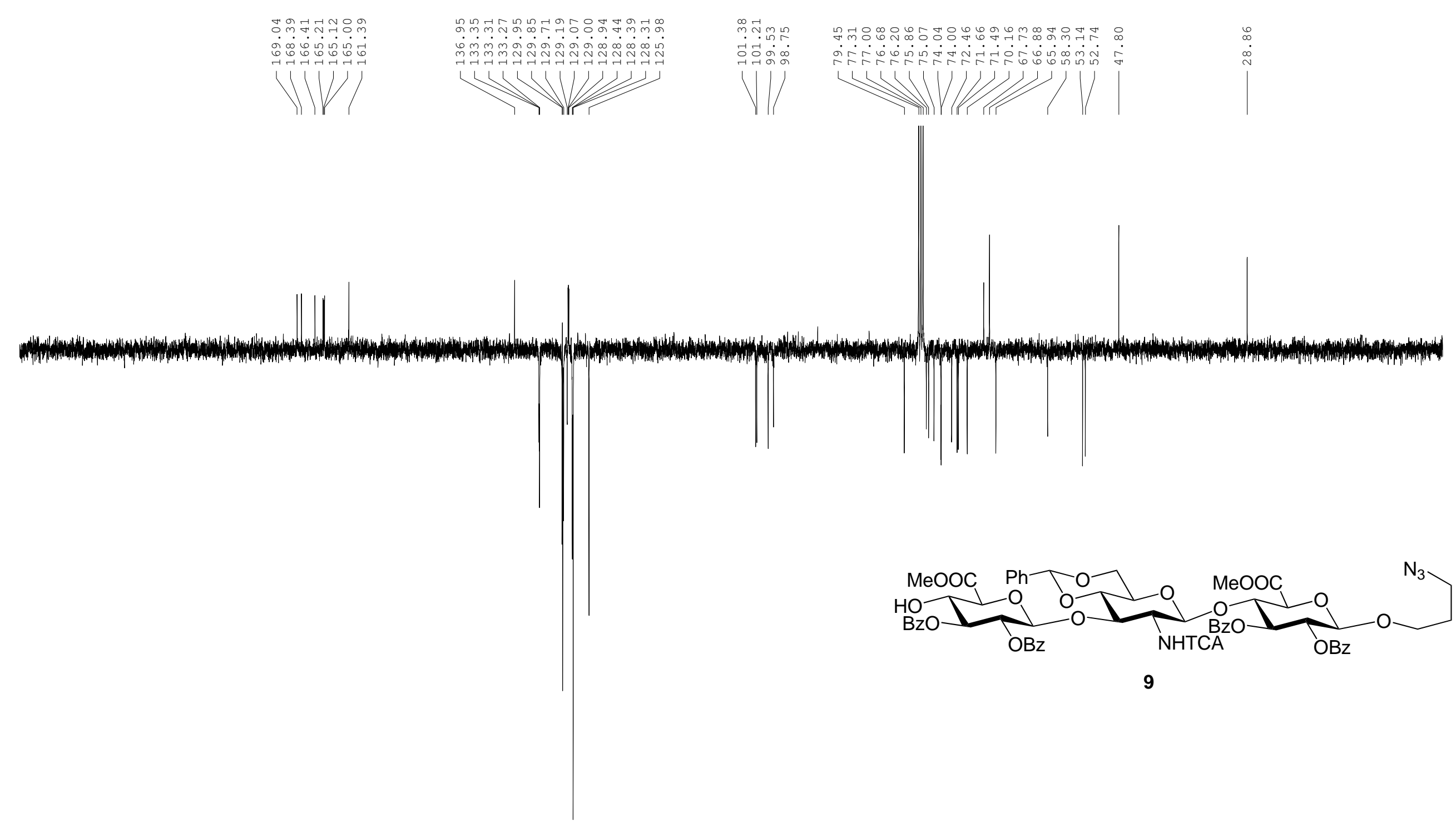














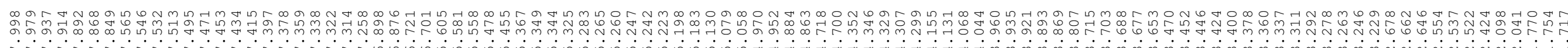

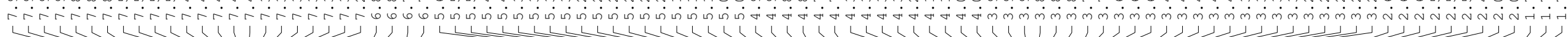

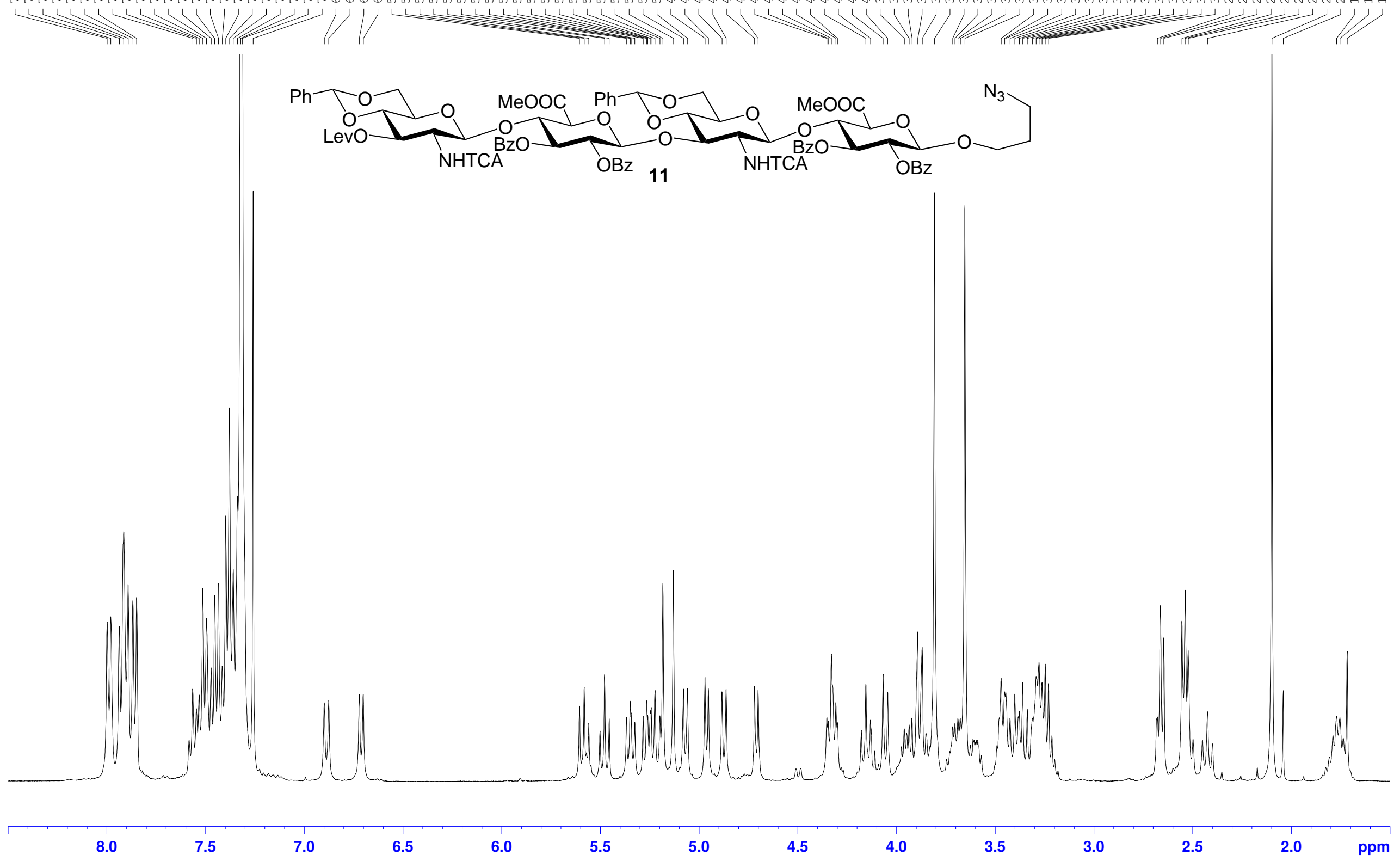




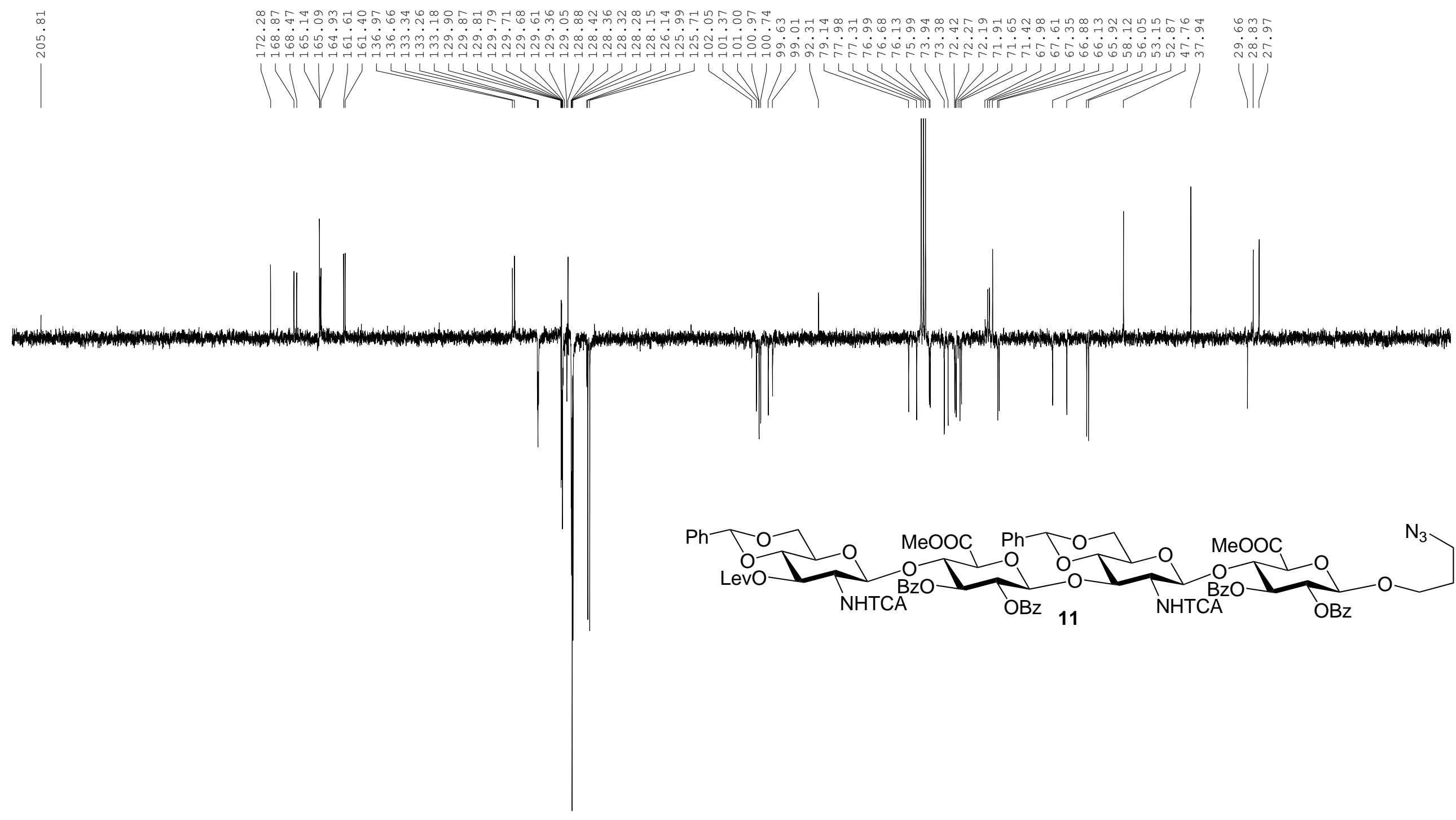




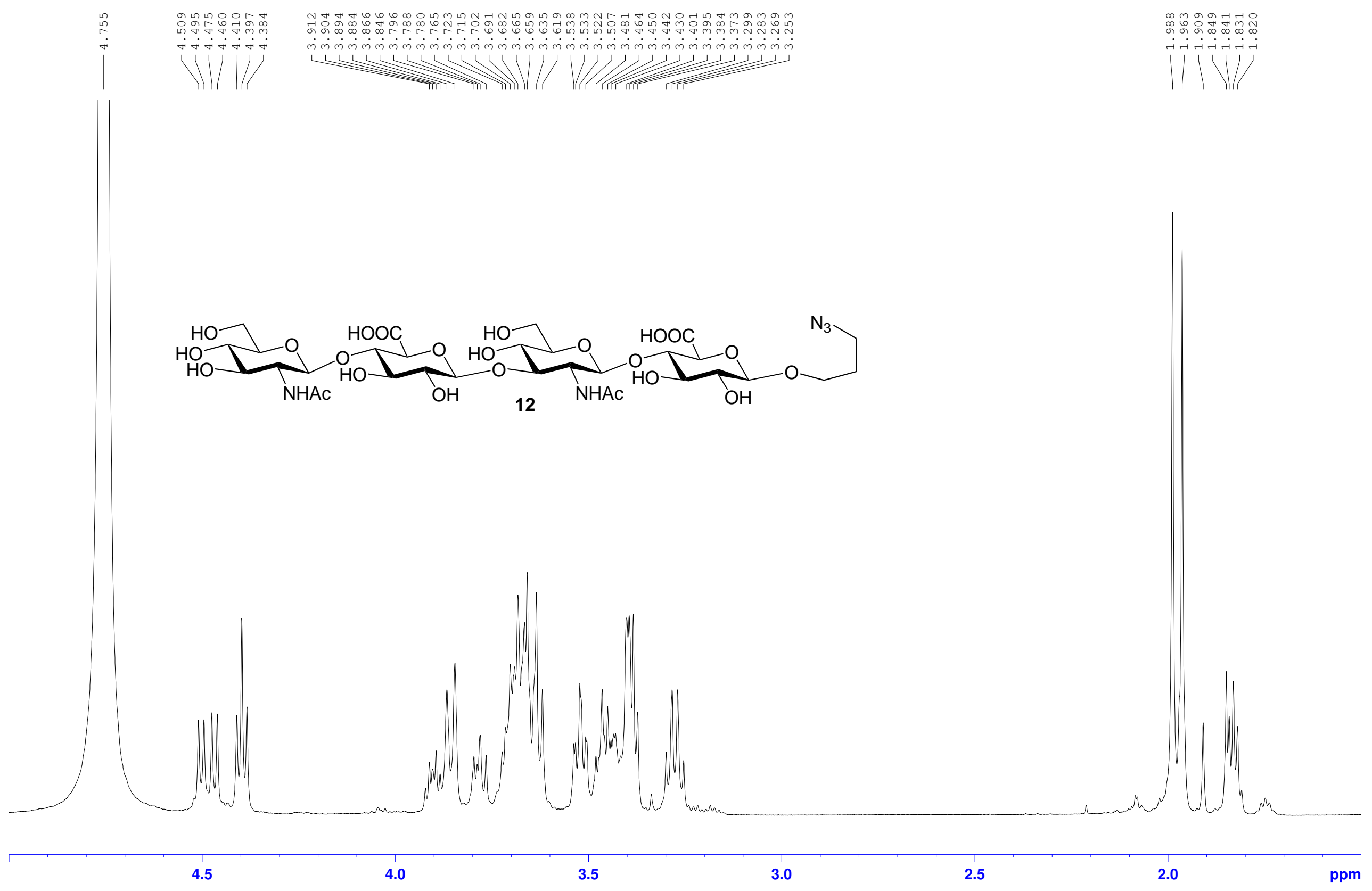




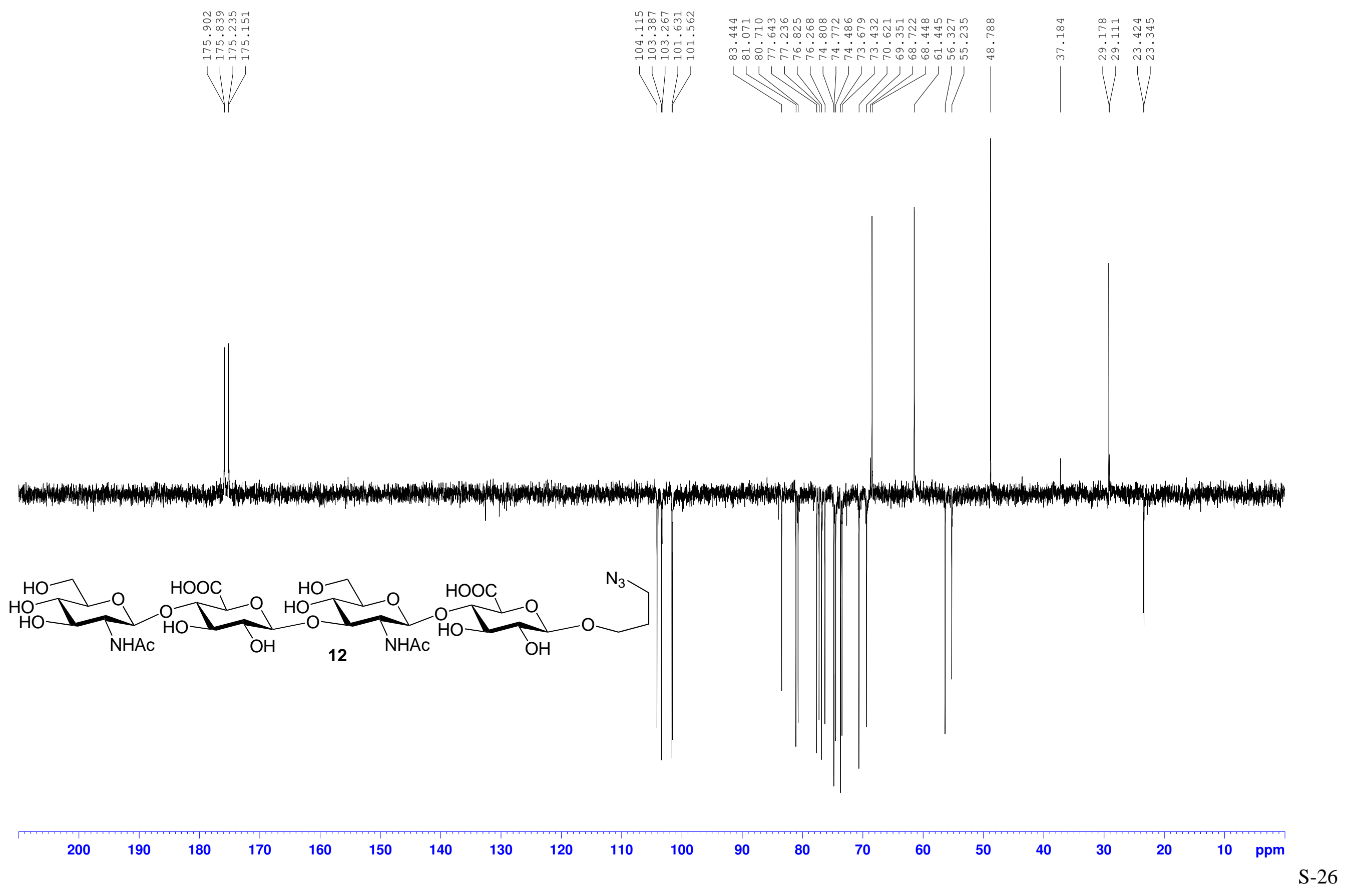




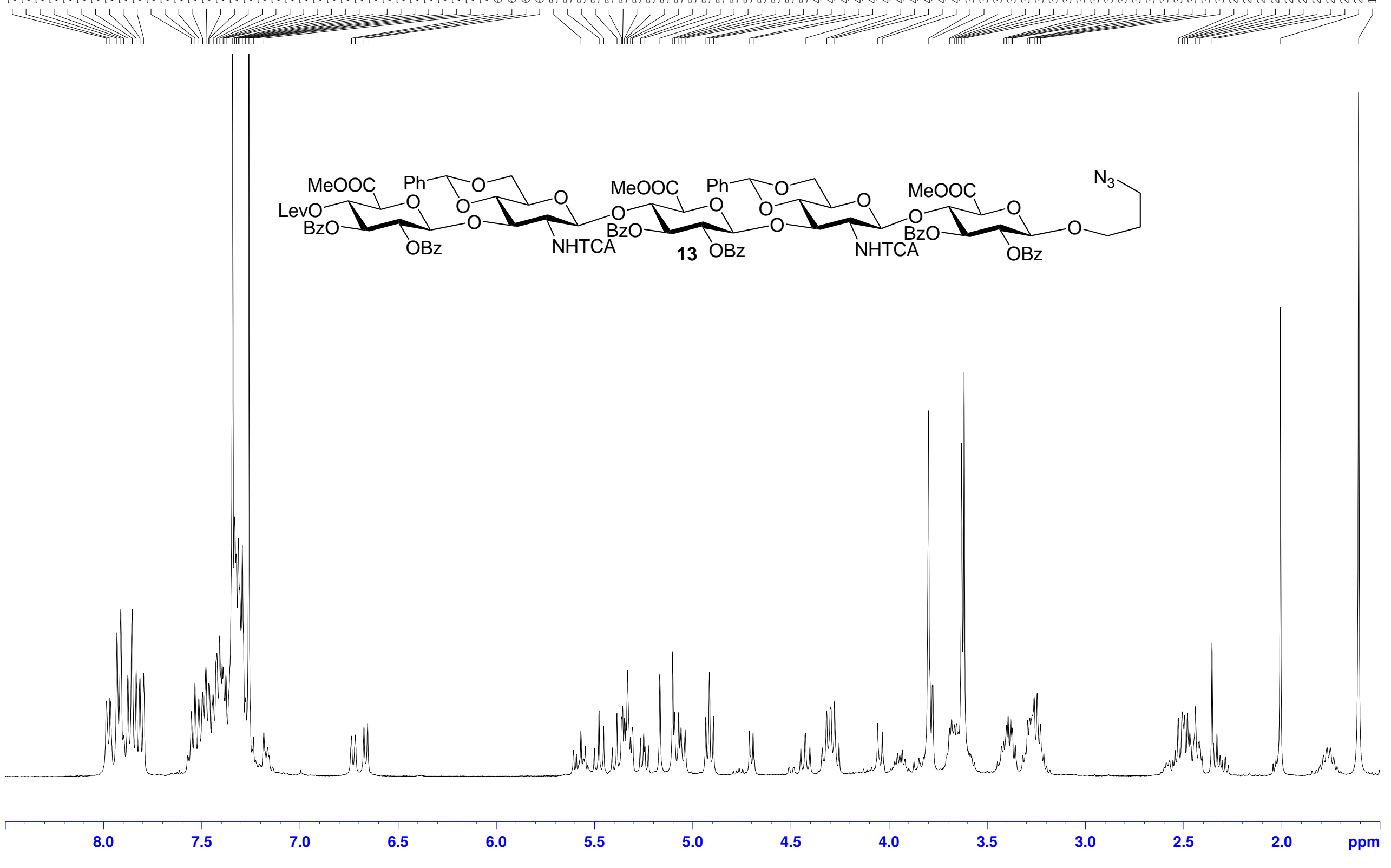




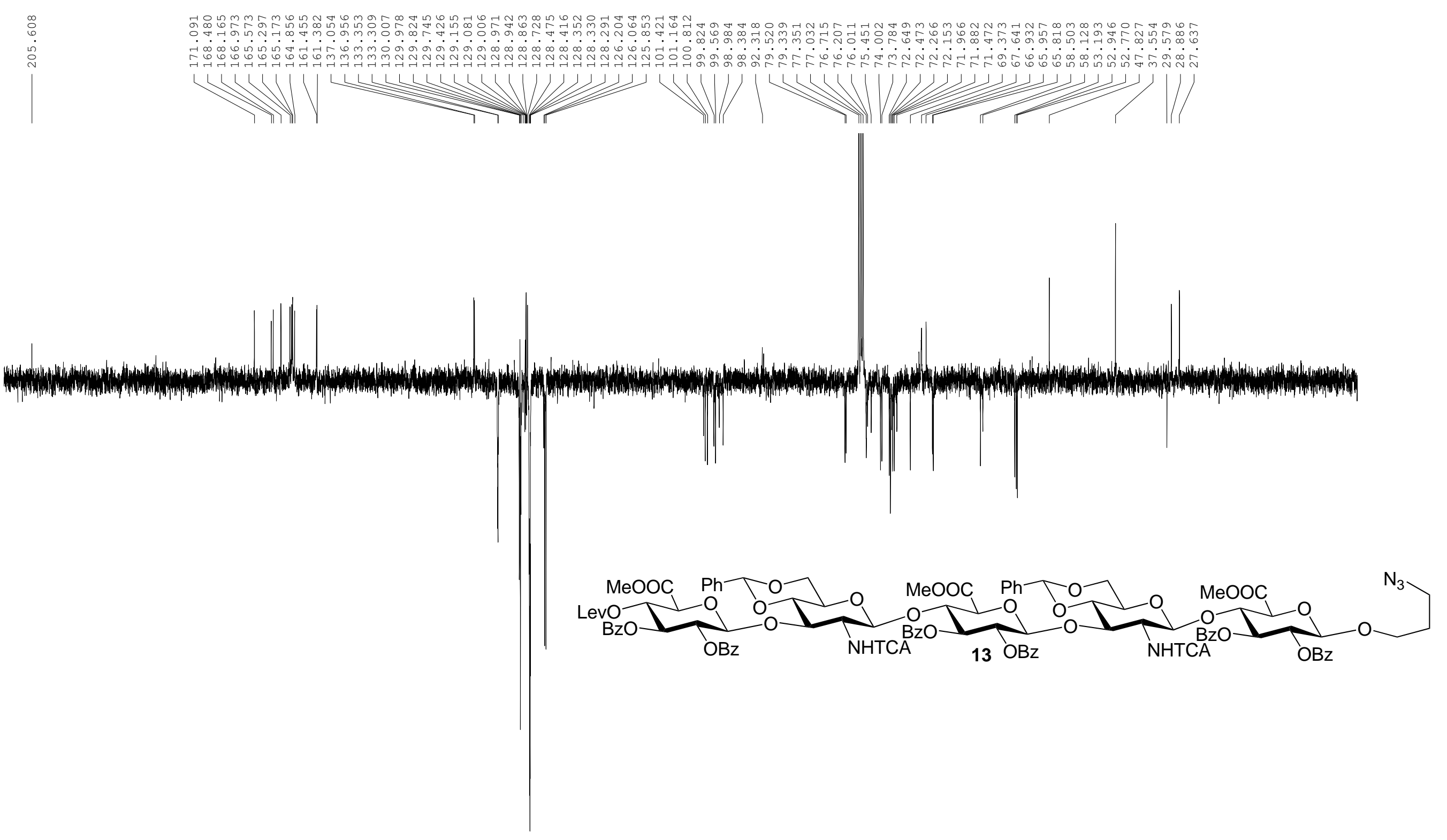




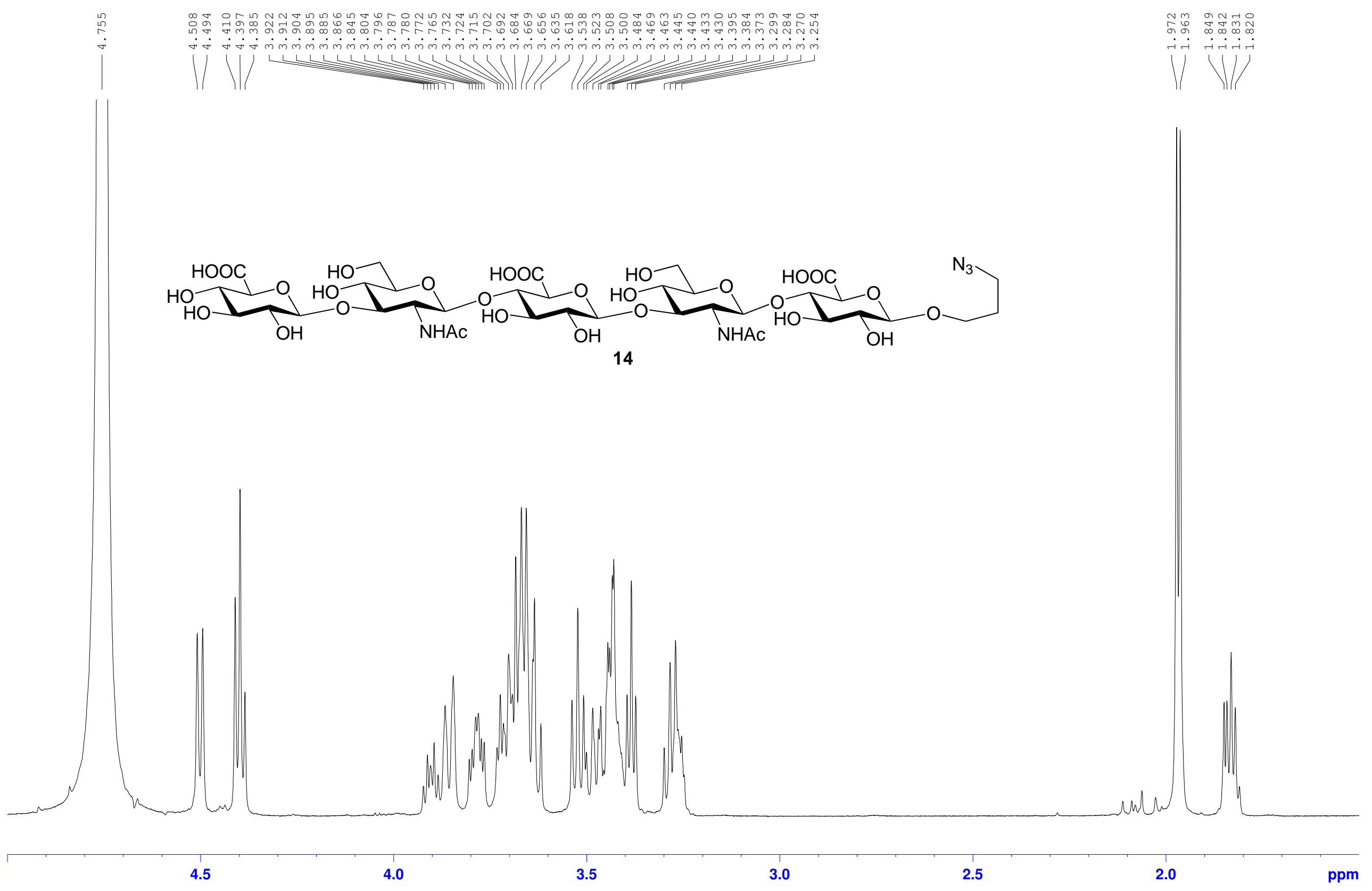




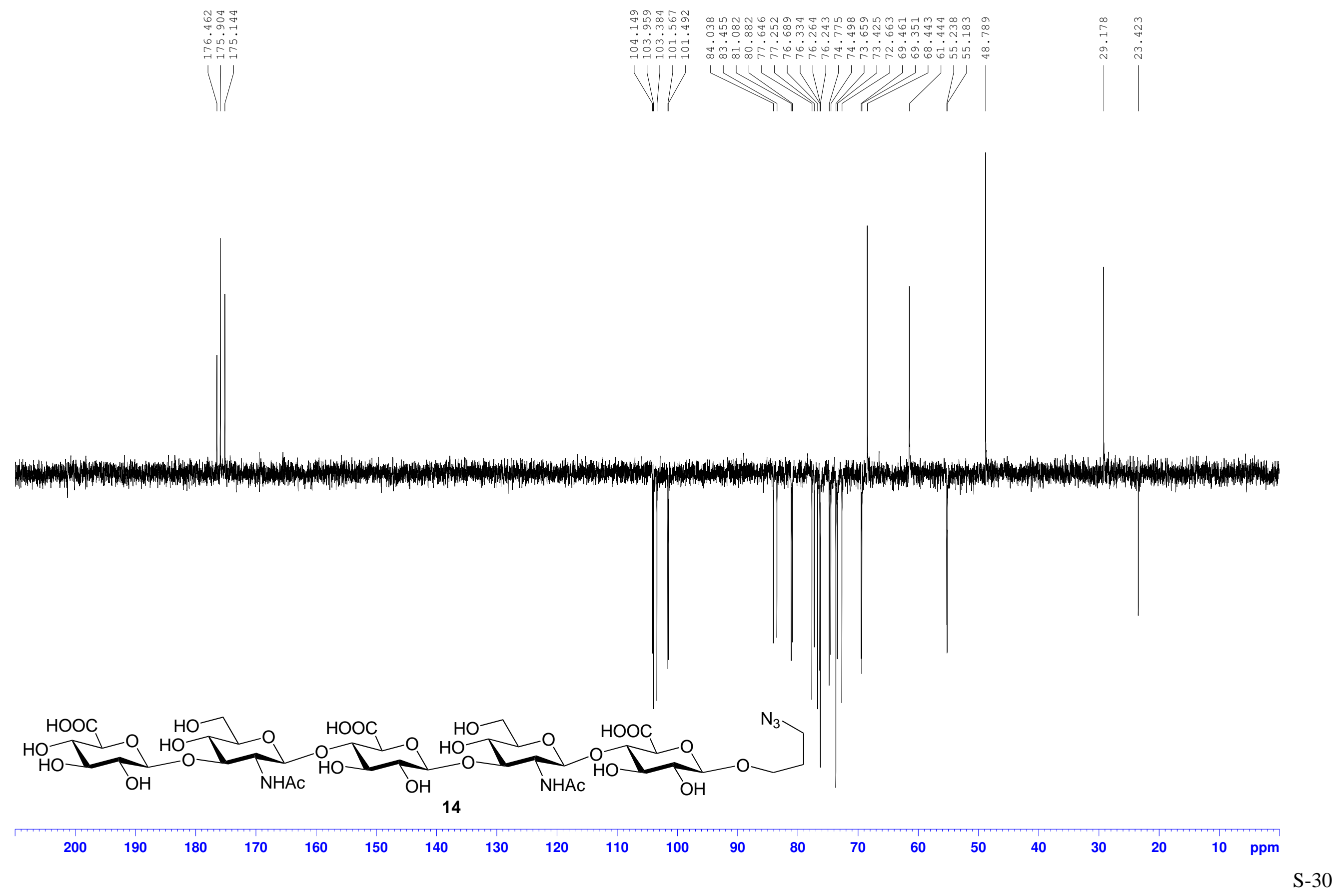

